\title{
Erratum to: Neointimal coverage and vasodilator response to titanium-nitride-oxide-coated bioactive stents and everolimus- eluting stents in patients with acute coronary syndrome: insights from the BASE-ACS trial
}

Pasi P. Karjalainen - Tuomas O. Kiviniemi - Tuomas Lehtinen • Wail Nammas • Antti Ylitalo • Antti Saraste · Jussi Mikkelsson •

Mikko Pietilä · Fausto Biancari · Juhani K. E. Airaksinen

Published online: 24 October 2013

(C) Springer Science+Business Media Dordrecht 2013

\section{Erratum to: Int J Cardiovasc Imaging}

DOI 10.1007/s10554-013-0285-8

Unfortunately, in the original online published article, the co-author names have been missed and they have been included in this Erratum.

The complete author group is provided here.

The online version of the original article can be found under doi:10. 1007/s10554-013-0285-8.

P. P. Karjalainen $(\varangle) \cdot$ T. O. Kiviniemi · T. Lehtinen •

W. Nammas · A. Ylitalo · J. Mikkelsson

Heart Center, Satakunta Central Hospital, Pori, Finland

e-mail: pasi.karjalainen@satshp.fi

T. O. Kiviniemi - T. Lehtinen · A. Saraste - M. Pietilä ·

J. K. E. Airaksinen

Department of Medicine, Turku University Hospital, Turku,

Finland

\author{
A. Saraste \\ Turku PET Centre, Turku University Hospital, Turku, Finland \\ F. Biancari \\ Department of Surgery, Oulu University Hospital, Oulu, Finland
}

